\title{
Biogeosystem Technique methodology and technological solutions for priority soil humic substances synthesis and healthy soil, water, and environment
}

Kalinitchenko V.P. ${ }^{1,4}$, Meshalkin V.P. ${ }^{2}$, Makarenkov D.A. ${ }^{3}$, Glinushkin A.P. ${ }^{4}$, Minkina T.M. ${ }^{5}$, Zinchenko V.E. ${ }^{6}$, Chernenko V.V. ${ }^{7}$, Mandzhieva S.S. ${ }^{5}$, Sushkova S.N. ${ }^{5}$, Il'ina L.P. ${ }^{8}$, Rykhlik A.E. ${ }^{1}$, Larin G.S. ${ }^{1}$, Grishina E.V. ${ }^{4}$

${ }^{1}$ Institute of Fertility of Soils of South Russia, Persianovka, Russia, kalinitch@mail.ru

${ }^{2}$ Mendeleev University of Chemical Technology of Russia, Moscow, Russia

${ }^{3}$ Institute of Chemical Reagents and High Purity Chemical Substances of National Research

Centre "Kurchatov Institute", Moscow, Russia

${ }^{4}$ Russian Research Institute of Phytopathology, Bolschije Wjasjomy, Russia

${ }^{5}$ Southern Federal University, Rostov-on-Don, Russia

${ }^{6}$ Federal Rostov Agrarian Research Center, Rassvet, Rostov Region, Russia

${ }^{7}$ Russian Research Institute of Viticulture and Winemaking, Federal Rostov Agrarian Research

Center, Rassvet, Rostov Region, Russia

${ }^{8}$ Southern Scientific Center of Russian Academy of Sciences, Rostov-on-Don, Russia

Keywords: Biogeosystem Technique, intra-soil milling, intra-soil pulse continuous-discrete watering, intra-soil dispersed waste recycling, priority conditions for humic substances

doi: 10.36291/HIT.2019.kalinitchenko.116

Humic substances interfaces in the "environment - soil - soil organic matter - soil mineral matter - technical means and technologies of agronomy, land reclamation, and waste utilization" are the great challenge concerning the current "Ecosphere - Technology" conflict caused by the current outdated imitative technological platform of land use. Copying Nature leads to soil degradation, water scarcity, improper waste management. This interfere the humic substances soil improving and plant fertilizing function. Mechanisms of the fundamental processes occurring at the "humic substances - mineral - water interfaces" remain elusive. The problem of humic substances is to be discussed understanding critically the larger-scale processes occurring at the mineral-water interfaces concerning the existing level of land use, assessing as a whole the Humankind technologies suitability for geospheres.

Technological platform of Noosphere is to be developed concerning a current multialternative business development model as becoming biosphere restricted. This fact is an adverse circumstance for the functioning of humic substances in soil as an agent of soil structure, nutrients turnover, and fertility.

For breaking through the fundamental shortcomings of current industrial technological platform and better result of humic substances apply we propose a new field of science and technology for world strategic development - Biogeosystem Technique (BGT*) - as the only opportunity to face the large-scale calls: sustainable evolution of healthy soil, water saving, high soil fertility, high quality environment to reduce the "organic matter - mineral - water" interfaces elusiveness and increase the Biosphere stability.

$\mathrm{BGT}^{*}$ - interdisciplinary institutional innovative integrated solutions, environmentally and economically sound, increasing the Earth biogeochemical flux and biogeosystems stability.

$B T^{\star}$ - implements a transcendental (uncommon for Nature) technical approach.

$\mathrm{BGT}^{*}$ - is proven in practice providing the synergy of theory and experiment.

BGT* provides: micro-aggregate soil illuvial horizon structure via intra-soil milling; reduced fresh water consumption via intra-soil pulse continuous-discrete watering; environmentally safe dispersed waste recycling for soil structuring and plant nutrition via intrasoil milling and intra-soil pulse continuous-discrete watering-chemigation; and priority conditions for humic substances function as an agent of soil organic matter synthesis and stability, soil health and high productivity. 